\title{
Altas Habilidades/Superdotação Percebidas pelas Máes nos Seus Filhos COM DeficiênCIA Visual ${ }^{1}$ \\ Giftedness Perceived bY Mothers of Visual Impaired Children
}

\author{
Betania Jacob Stange LOPES ${ }^{2}$ \\ Maria Stella Coutinho de Alcantara GIL ${ }^{3}$
}

\begin{abstract}
RESUMO: este estudo teve por objetivo verificar se mães de crianças com deficiência visual identificam características e comportamentos comuns àquelas com altas habilidades/superdotação. Participaram deste estudo três mães, com idade entre 37 a 46 anos, com nível educacional igual ou superior ao Ensino Fundamental completo. O estudo foi realizado na sede de uma Organização Não Governamental que atende pessoas com deficiência visual em uma cidade do interior do estado de São Paulo. Foram empregados na coleta de dados: Ficha de Identificaçấo e Caracterização de Pais; Formulário de Identificação de Indicadores de altas habilidades/superdotação; Subtestes das Escalas Verbais, das Escalas Wechsler de Inteligência (WISC III), adaptadas para pessoas com deficiência visual. Foi elaborada uma planilha com as características da Teoria dos Três Anéis, de Renzulli, e analisadas as respostas das mães a partir desta Escala de Indicadores, comparada com os resultados dos subtestes das Escalas Verbais do WISK III, adaptada para pessoas com deficiência visual. A escolha das máes indica que estes têm altas expectativas em relação às potencialidades de seus filhos. A despeito da deficiência visual das crianças, as mães consideram seus filhos plenamente capazes. Os resultados permitem a discussão da possível dupla excepcionalidade decorrente da associação da deficiência visual com altas habilidades/superdotação.
\end{abstract}

PALAVRAS-CHAVE: Educação Especial. Altas Habilidades/Superdotação. Deficiência Visual.

\begin{abstract}
This study aimed to verify whether mothers of children with visual impairment identify characteristics and behaviors common to those with giftedness. Three mothers aged 37-46 years participated in the study. They all have educational level equal to or higher than complete elementary education. The study was conducted at the headquarters of a Non-Governmental Organization that serves people with visual impairment in a city in the state of São Paulo. Data were collected through: Identification Form and Mothers' Characterization; Giftedness Indicators Identification Form; Wechsler Intelligence Scales III (WISC) Verbal Scale Subtests, adapted for visually impaired people. A spreadsheet with the characteristics of the Theory of the Three Rings by Renzulli was elaborated to analyze the mothers' response from this Indicators Scale, and was compared with the results of the WISK III Verbal Scale subtests. The mothers' response indicates that they have high expectations regarding their children's potential. Despite the children's visual impairment, the mothers consider them fully capable. The results support the discussion of possible dual exceptionality emerging from the visual impairment associated with giftedness.
\end{abstract}

KEYWORDS: Special Education. Giftedness. Visual Impairment.

\section{INTRODUÇÁO}

O expressivo avanço nas pesquisas da área da Educação Especial enseja a busca das características de "dupla excepcionalidade" em diferentes populaçóes. Essa designação, apresentada por Shang-Ping e Anjoo (1992), traz subjacente a possível contradição quando a expressão - dupla excepcionalidade - se refere a altas habilidades/superdotação $(\mathrm{AH} / \mathrm{S})$ e deficiência visual (DV) (SILVERMAN, 2003). A discussão da possibilidade de dupla excepcionalidade foi abordada neste trabalho, que teve por objetivo identificar as características conjugadas de AH/S e DV em crianças pela perspectiva da própria mãe.

\footnotetext{
${ }^{1}$ http://dx.doi.org/10.1590/S1413-65382216000200005

${ }^{2}$ Doutoranda em Educação Especial pela Universidade Federal de São Carlos, São Carlos, SP, Brasil. betania.stange@unasp.edu.br

${ }^{3}$ Docente do Programa de Pós-Graduação em Educação Especial e Programa de Pós-Graduação em Psicologia da Universidade Federal de São Carlos. Centro de Educação e Ciências Humanas, Departamento de Psicologia, São Carlos, SP, Brasil. stellagil@uol.com.br
} 
Diferentes autores vêm destacando os motivos pelos quais a identificação da dupla excepcionalidade nem sempre ocorre. Para Whitmore e Maker (1985), quatro fatores podem justificar a dificuldade: expectativas estereotipadas; atrasos no desenvolvimento; informaçóes incompletas sobre as crianças; e ausência de oportunidade para demonstração de evidências de capacidades mentais superiores. A esses podem ser acrescentados quatro outros fatores, descritos por Johnson e Corn (1989): o conhecimento limitado dos pais sobre o potencial dos filhos (por desconhecerem ou acharem impossível a conjunção de duas características da excepcionalidade); a falta de experiência de profissionais em lidar com a dupla excepcionalidade (AH/S e DV); o uso de métodos ou instrumentos inapropriados para detectar pontos fortes dos alunos; e a limitação financeira para acomodação dessas crianças em programas especiais por necessitarem de uma variedade maior de recursos educacionais.

\subsection{DeSENVOLVIMENTO DA CRIANÇA COM DEFICIÊNCIA VISUAL}

O desenvolvimento da criança com DV tem sido alvo de estudos que podem ser organizados em duas abordagens, de acordo com Pérez-Pereira e Conti-Ramsden (2008). A primeira delas atribui as diferenças entre o desenvolvimento de crianças videntes e de crianças com DV a um déficit associado à deficiência. Essa perspectiva é ressaltada quando se pensa em um mundo de videntes que prioriza o uso da visão na aquisição do conhecimento.

A segunda abordagem contempla a possibilidade de diferentes rotas ou estilos de desenvolvimento. Assim, a criança com DV pode contrabalançar a ausência ou diminuição de informação visual com maior atenção a outras fontes de informação, ou seja, utilizar estratégias diversas e diferentes estilos de aprendizagem. Pode-se levar em consideração a grande variação de características pessoais e ambientais que influenciarão o desenvolvimento da criança com DV, inclusive a possibilidade de outras Necessidades Educacionais Especiais não ligadas à deficiência visual, incluindo as $\mathrm{AH} / \mathrm{S}$.

Warren (1994) defende que nenhuma das duas abordagens pode ser ignorada ou adotada isoladamente, uma vez que há metas de desenvolvimento comuns a todas as crianças, ao mesmo tempo em que a criança com DV se reorganiza e cria uma adaptação própria de acordo com as suas características. $\mathrm{O}$ autor apresenta fatores que podem influenciar a avaliação da inteligência de crianças com DV ligados ao ambiente, às características pessoais do indivíduo, à idade em que se dá a perda visual e, ao motivo da perda visual, entre outros.

Vygotsky (1934/1997) enfatizou que a deficiência visual modifica a relação do homem com o mundo, e a diferença biológica não é o principal fator que implica desenvolvimento limitado ou não desenvolvimento da pessoa com DV, mas sim a inabilidade para o desenvolvimento da conduta social da criança. Para o autor, há necessidade de incorporar a criança à vida cotidiana e criar a compensação do seu defeito. $\mathrm{O}$ seu desenvolvimento não pode ser caracterizado apenas como o desenvolvimento normal subtraindo-se a visão, pois a pessoa com deficiência visual pode atingir os mesmos níveis de desenvolvimento por caminhos diferentes. Quando as vias de apreensão do mundo não estão íntegras, o indivíduo pode escolher outras que estejam nessa condição, superando assim seus limites acima da média esperada na sociedade.

A atualidade do exposto por Vygotsky nos idos de 1930 pode ser verificada na discussão proposta por Warren (1994) com base em pesquisas empíricas sobre o desenvolvimento 
de pessoas com DV. A posição de cada um dos autores converge no que se refere ao atraso no desenvolvimento do sujeito com DV, quando comparado com o vidente, não como consequência direta da deficiência visual, mas das limitaçóes de suas experiências ligadas ao ambiente.

Um mundo organizado para dar à visão a primazia do acesso às informações para crianças (videntes) se apresenta como grande desafio para o desenvolvimento de crianças com DV. Estas, desde o nascimento, estão em um mundo organizado para pessoas com sistema visual íntegro, embora não seja o único meio de acesso à informação (BATISTA; ENUMO, 2000). Como todas as crianças, aquelas com DV podem contar com o sistema háptico, o sistema auditivo e a linguagem para o seu desenvolvimento, com o importante destaque de que para elas a integração desses sistemas é a condição de desenvolvimento e de aprendizagem.

Mais especialmente, em se tratando do desenvolvimento cognitivo das crianças com DV, os autores indicam a existência de atrasos quando estas são comparadas com crianças videntes. Considerando este parâmetro, a cognição da criança com DV é avaliada como pobre, deficiente ou atrasada (NAVARRO; MILLÁN, 2007). Entretanto, os atrasos identificados foram percebidos em áreas específicas que exigiam da criança com DV maior imaginação, criatividade (RETTIG, 1994) e velocidade na aquisição de algumas dimensóes do desenvolvimento cognitivo (WARREN, 1994). Nunes e Lomônaco (2008) afirmaram que muitas das dificuldades ou defasagens se devem à falta de informação, e não à capacidade de processá-la.

A natureza da relação entre defasagens cognitivas e processamento é convergente com aquela considerada por Lewis (2003) ao afirmar que os envolvidos no processo educacional de pessoas com deficiência visual têm, por falta de mais informaçóes, dificuldades tanto na caracterização das necessidades para o acesso visual quanto na identificação de possíveis deficiências associadas, entre elas as AH/S. Esta discussão reposiciona o foco nas oportunidades que os adultos organizam para o desenvolvimento das crianças e, portanto, para o modo como concebem ou percebem a potencialidades das crianças com DV.

O fato de se considerar que o desenvolvimento das crianças cegas não decorre diretamente da deficiência visual amplia possibilidades de se discutir que elas apresentam AH/S tal como os alunos videntes. A criança com DV não apenas compensaria o que falta, mas poderia supercompensar seus limites a um nível acima da média esperada para a sociedade em que está inserida (COELHO; BARROCO; SIERRA, 2011).

A possibilidade de associação da deficiência visual com altas habilidades ressalta ainda mais a necessidade de apoio pedagógico especializado tanto em classe comum quanto em sala de recursos. O exame dos estudos realizados sobre as competências, habilidades e capacidades das crianças e jovens com deficiência visual produzidos dos anos 70 até 2008 permitem afirmar que há muito a conhecer sobre esta população. Neles, se destacam as perguntas sobre as possíveis deficiências associadas à cegueira ou à baixa visão intensivamente respondidas quando trataram da deficiência intelectual (OUROFINO, 2007; SMITH, 2008). Especificamente, a associação com AH/S está ainda por ser explorada. Tratar das possibilidades de pessoas com deficiência visual apresentarem, também, características de superdotação pode ser uma via de ampliação do conhecimento desta população pela Educação Especial e, em decorrência, do aumento potencial de oferta de condiçôes apropriadas de desenvolvimento para essas crianças. 


\subsection{Altas habilidades/Superdotaçáo}

O tema "altas habilidades/superdotação" (AH/S) não é novo no contexto educacional e suscita muitas divergências por parte dos especialistas na área quanto às terminologias empregadas (GERMANI, 2006). Até a década de 70, o termo era utilizado para identificar indivíduos com escores de quociente de inteligência (QI) acima de 135 no teste de inteligência de Stanford-Binet, sobretudo em se tratando de pessoas em fase de escolarização básica. A identificação dos alunos com altas habilidades/superdotação tinha dois objetivos específicos: fornecer àqueles com potencial as possibilidades de desenvolvimento cognitivo e aumentar a reserva social de pessoas que ajudariam a resolver os problemas da sociedade contemporânea como produtores do conhecimento. Nesse período, surgiram os primeiros questionamentos sobre o predomínio do uso apenas de um critério - o escore do QI - para identificar alunos com superdotação (RENZULLI, 2004).

Renzulli (1986) reafirma a ideia de que a superdotação não poderia ser identificada somente por meio de testes de inteligência, mas deveria considerar outros pontos básicos para a investigaçáo de fatores a serem combinados entre si. $\mathrm{O}$ autor propôs um modelo de análise da superdotação que denominou "Teoria dos Três Anéis" e que foi fundamentado na confluência de três traços de comportamento: habilidade acima da média, em alguma área do conhecimento, em relaçáo aos pares da mesma idade e origem social e cultural; envolvimento com a tarefa, implicando a motivação e vontade de realizar uma tarefa, perseverança e concentração; e criatividade, tal como pensar em algo diferente e ver novos significados e implicaçóes, e retirar ideias de um contexto e usá-las em outro. Esses comportamentos foram representados graficamente como estando localizados na intersecção de três círculos denominados "Anéis" (ALMEIDA; CAPELLINI, 2005; VIRGOLIM, 2007). No Modelo, os três anéis (círculos) foram organizados e superpostos a um fundo com padrão xadrez (ver Figura 1). Este representa a interação de fatores ambientais com fatores de personalidade favorecedora do aparecimento da superdotação, que está localizada na área de intersecção dos círculos no diagrama.

Segundo Renzulli (1978), as crianças que possuem ou são capazes de desenvolver os traços de comportamentos que compóem a Teoria dos Três Anéis e aplicá-las a qualquer área potencialmente valorizada do desempenho humano são superdotadas ou talentosas. Ao elaborar o modelo, a sua intenção "[...] era transmitir a ideia de que os candidatos ao atendimento especial náo precisam manifestar todos os três grupamentos, mas apenas serem identificados como capazes de desenvolver essas características" (RENZULLI, 2004, p.85). 


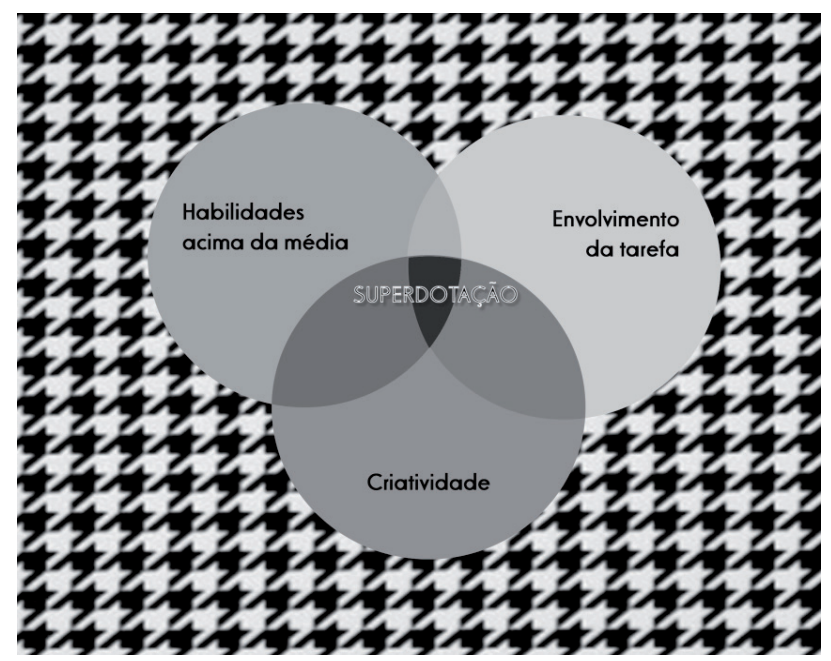

Figura 1 - Representação da Teoria dos Três Anéis (RENZULLI, 1978).

Fonte: Renzulli (1986, p.8).

\subsection{Família E as altas habilidades/superdotaÇáo}

O contexto familiar é o primeiro espaço de socialização do ser humano, ambiente no qual as crianças encontram as bases para o seu desenvolvimento biopsicossocial (DESSEN, 1997; KREPPNER, 1992, 2000, 2003), e é exatamente neste contexto que vão ser notados os primeiros sinais das habilidades dos filhos.

Segundo Rodrigo e Palácios (2003), nas interaçôes com os seus familiares as crianças se descobrem e exploraram o mundo que as cerca. Para as crianças que apresentam indicadores de AH/S, o acompanhamento dos pais é imprescindível a fim de atender às necessidades cognitivas e socioafetivas e para evitar os desajustes no desenvolvimento e a perda de talentos. O extravio de talentos, segundo Silverman (2003), se dá como consequência da falta de informação dos pais que apresentam dificuldades em lidar com essa necessidade educacional de seu filho.

Há diferenças nas reaçóes dos pais em relação à superdotação de seus filhos. Por um lado, alguns pensam que seus filhos devem aproveitar a infância e adolescência sem nenhuma interferência educacional diferençada e não demonstram expectativas em relação ao potencial que poderia ser desenvolvido, o que pode gerar um desajuste de ordem emocional e social. Em contrapartida, outros pais destacam acentuadamente as habilidades dos filhos a ponto de nunca estarem satisfeitos com os resultados que eles obtêm, o que compromete o bem-estar psicológico da criança (WINNER, 1998).

Objetivando auxiliar os pais nessa trajetória, Rodrigo e Palácios (2003, p.36) ressaltaram quatro funções básicas dos pais na relação com seus filhos superdotados: a) garantir seu saudável crescimento e sua socialização com as condutas básicas de comunicação, diálogo e simbolização; b) proporcionar um clima de apoio e afeto; c) oferecer estimulação para que seu filho alcance a capacidade para relacionar-se competentemente com o meio social e possam responder às demandas e exigências de adaptação ao mundo em que vive; d) dar oportunidade 
aos filhos de participação em outros contextos educativos que compartilharão com a família a tarefa de educação dos filhos.

A atenção preconizada para a construção de ambientes ricos e favorecedores do desenvolvimento que encontramos para outras "deficiências" é igualmente proposta para aqueles com indicadores de AH/S. O desafio de lidar com AH/S é enfrentado pelos pais e também pela comunidade escolar de forma geral, e ambos necessitam de orientação para educar filhos e alunos adequadamente.

Em paralelo com a importância da precocidade na abordagem de outras deficiências, Aspesi (2007) esclarece que quanto mais cedo forem identificados os aspectos que indiquem AH/S e for oferecido apoio, mais resiliente a criança se tornará aos eventos negativos que acontecem, tornando-se apta para utilizar seus talentos a fim de alcançar a satisfação e produtividade em sua vida. A identificação precoce das AH/S auxilia, portanto, o desenvolvimento de suas capacidades e o trabalho conjunto da escola e da família (GUENTHER, 2003; HALLAHAN; KAUFFMAN, 2003) é essencial no atendimento da população de superdotados.

Confrontar as propostas de análise do desenvolvimento de crianças com deficiência visual e de crianças com indicadores de AH/S permite verificar a confluência de afirmaçóes e de propostas de abordagem dessas duas condiçôes. Para ambas, o contexto social do desenvolvimento é a pedra de toque da potencialidade das crianças (WARREN, 1994; VYGOTSKY, 1934-1997; LEWIS, 2003; NAVARRO; MILLÁN, 2007; OUROFINO, 2007; NUNES; LAMÔNACO, 2008). São destacados os papéis da família e da escola no oferecimento de ambientes potencialmente ricos e instigantes (SILVERMAN, 1997; WINNER, 1998; GUENTHER, 2003; HALLAHAN; KAUFFMAN, 2003; RODRIGO; PALÁCIOS, 2003) e o ganho da identificação precoce das necessidades das crianças. Entretanto, o exame da literatura indica a escassez de estudos sobre a dupla excepcionalidade quando se trata do grupo de pessoas que reuniria a deficiência visual e indicadores de AH/S, uma possibilidade considerada por Ourofino (2007).

A possibilidade de associação entre as condiçóes da deficiência visual e das AH/S suscita questóes sobre a identificação da dupla excepcionalidade. Uma abordagem inicial da questão, proposta neste trabalho, considerou a primazia da família na convivência com as crianças desde o nascimento e a possibilidade de atendimento especializado a crianças com DV e família. Foi considerado que uma das perguntas que poderia se constituir em ponto de partida para a abordagem da dupla excepcionalidade DV-AH/S seria sobre a percepção dos pais a respeito das características $\mathrm{AH} / \mathrm{S}$ dos seus filhos com DV.

As mães de crianças com DV percebem características e comportamentos que indicam a presença de AH/S em seus filhos? Seria possível considerar a percepção das mães de crianças com DV em relação à avaliação de aspectos cognitivos do seu desempenho? Para buscar respostas às perguntas, foi apresentado como objetivo desta pesquisa verificar se mães de crianças com DV identificam características e comportamentos comuns a crianças com AH/S. 


\section{Método}

\subsection{Participantes}

Participaram deste estudo três mães, que serão designadas pelos códigos formados pela letra P seguida da idade de seu filho com DV (P07, P08 e P11), cujas características foram apresentadas no Quadro 1. O Quadro 1 está constituído por seis colunas, a primeira indicando o código de identificação dos participantes e as demais apresentando, em sequência, a idade e escolaridade das mães respondentes, além de informaçóes sobre o diagnóstico de deficiência visual dos filhos. A seleção inicial dos participantes considerou a disposição e disponibilidade dos responsáveis em realizar as atividades que lhes seriam propostas.

A pesquisa foi aprovada pelo Comitê de Ética da Universidade Federal de São Carlos (CEP/UFSCar) com o Protocolo n. ${ }^{\circ}$ 10970519.9.0000.5504. Os pais que livremente decidiram participar e permitiram a participaçáo dos seus filhos assinaram o Termo de Consentimento Livre e Esclarecido (TCLE).

\begin{tabular}{|l|l|l|l|l|l|}
\hline \multicolumn{3}{|c|}{ Máes } & \multicolumn{3}{c|}{ Filhos(as) com DV } \\
\hline Código & Idade & \multicolumn{1}{|c|}{ Escolaridade } & Idade & Sexo & \multicolumn{1}{c|}{ Diagnóstico DV } \\
\hline P07 & 37 & $\begin{array}{l}\text { Ensino Médio } \\
\text { Completo }\end{array}$ & 07 & F & Toxoplasmose \\
\hline P08 & 46 & $\begin{array}{l}\text { Ensino Médio } \\
\text { Completo }\end{array}$ & 08 & M & $\begin{array}{l}\text { Toxoplasmose } \\
\text { Congênita }\end{array}$ \\
\hline P11 & 37 & $\begin{array}{l}\text { Ensino Fundamental } \\
\text { Completo }\end{array}$ & 11 & F & Descobriu com 7 anos \\
\hline
\end{tabular}

Quadro 1- Caracterização dos participantes, Organização Náo Governamental no interior do estado de São Paulo, 2013.

Fonte: Elaboração própria.

\subsection{LOCAL}

O estudo foi realizado na sede de uma Organizaçáo Não Governamental (ONG), que atendia aproximadamente 70 pessoas com deficiência visual e família. Estava localizada em uma cidade do interior do estado de Sáo Paulo e foi escolhida pela possibilidade de proporcionar uma amostra significativa de pais e filhos com DV.

\subsection{INSTRUMENTOS}

Para a seleção/inclusão e caracterização dos participantes e para a coleta de dados foram empregados: (a) Ficha de Identificação de Mães - que teve como objetivo a obtenção de dados de identificação e informaçóes de contato (nome, telefone, endereço eletrônico, entre outras); (b) Ficha de Caracterização de Máes - com objetivo de registro de informaçôes sobre as mães, tais como: idade, escolarizaçáo, renda e conceitos sobre o tema; (c) Formulário de Identificação de Indicadores de Altas Habilidades/Superdotação; d) cinco subtestes adaptados para pessoas com deficiência visual, por Nascimento (2004) das Escalas Verbais da Wechsler Intelligence Scale for Children III (WISK III) (informação; semelhanças; aritmética; vocabulário; compreensão; e dígitos). Os três primeiros instrumentos ( $\mathrm{a}, \mathrm{b}$ e c) foram especialmente ajustados para este trabalho com base naqueles propostos por Marques (2011). 


\subsection{Procedimentos}

\subsubsection{Familiarizaçáo com a ONG e Contato com os pais}

Inicialmente, foi proposta uma reunião com os gestores da ONG para esclarecimento dos procedimentos de pesquisa seguida da submissão e aprovação da pesquisa pelo CEP/ UFSCar. Recebida a permissão para realização da pesquisa, foram apresentados aos pais da ONG o objetivo da pesquisa, os procedimentos de coleta de dados, os cuidados éticos necessários e, ao final da reuniáo, eles optaram por participar ou náo da pesquisa. Posteriormente, nova reuniáo foi realizada com os pais que aceitaram participar para preenchimento dos instrumentos da pesquisa.

\subsubsection{Seleçáo dos PaRTiCipantes E COLETA De dados}

Dos dezenove pais que concordaram em participar com seus filhos, foram selecionadas aqueles que atenderam aos critérios estabelecidos para indicativo das AH/S. Após a coleta de dados com todos os pais, os nove filhos cujos pais assinalaram o maior número de indicadores de AH/S foram convidados a participar de uma aplicação dos subtestes do WISC III, adaptados para pessoas com DV por Nascimento (2004). Dos noves filhos, três obtiveram escores nos subtestes (P07, P08 e P11) e cada uma das mães participou da coleta de dados. A aplicação do teste e a avaliação dos escores obtidos foram realizadas pelas psicólogas da ONG.

Os filhos dos pais cujas respostas aos questionários e formulários não atenderam ao critério de inclusão não foram submetidos às provas posteriores. Foi realizada uma reunião com esses pais visando apresentar o conjunto dos itens para os quais cada participante destacou o potencial positivo e favorável para o desenvolvimento desse grupo de alunos. $\mathrm{O}$ objetivo foi devolver as informaçóes relevantes para que os pais percebessem favoravelmente o desempenho dos seus filhos de acordo com as respostas oferecidas aos instrumentos empregados.

\subsection{ANÁLISE DOS DADOS}

As respostas das mães aos questionários e ao Formulário de Identificação foram organizadas em uma planilha que especificava em suas colunas os conjuntos de indicadores associados a cada uma das características representadas pela Teoria dos Três Anéis (RENZULLI, 1978). As informaçóes classificadas de acordo com a planilha foram organizadas no Quadro 2. Dele constam seis colunas que apresentam três conjuntos de informaçôes, classificados de acordo com os indicadores e o respectivo Anel a eles correspondente, conforme proposto por Marques (2011). As respostas das mães obtidas pelo preenchimento do Formulário de Indicadores foram examinadas com referência aos itens do Quadro 2 e, posteriormente, foram cotejadas com os resultados das crianças obtidos nos subtestes da Escala Verbal do Teste WISK III, adaptada para pessoas com DV por Nascimento (2004). 


\begin{tabular}{|c|c|c|c|c|c|}
\hline Indicador & $\begin{array}{l}\text { Habilidades Acima } \\
\text { da Média }\end{array}$ & Indicador & Criatividade & Indicador & $\begin{array}{l}\text { Envolvimento com a } \\
\text { Tarefa }\end{array}$ \\
\hline 01 & $\begin{array}{l}\text { Aprende fácil e } \\
\text { rapidamente. }\end{array}$ & 02 & $\begin{array}{l}\text { Original, imagina- } \\
\text { tivo, criativo, não } \\
\text { convencional. }\end{array}$ & 03 & $\begin{array}{l}\text { Amplamente informa- } \\
\text { do; informado em áreas } \\
\text { comuns. }\end{array}$ \\
\hline 06 & $\begin{array}{l}\text { Persuasivo, capaz } \\
\text { de influenciar os } \\
\text { outros. }\end{array}$ & 04 & $\begin{array}{l}\text { Pensa de forma in- } \\
\text { comum para resolver } \\
\text { problemas. }\end{array}$ & 05 & $\begin{array}{l}\text { Persistente, independente, } \\
\text { autodirecionado (faz coisas } \\
\text { sem que seja mandado). }\end{array}$ \\
\hline 07 & $\begin{array}{l}\text { Mostra senso } \\
\text { comum; pode não } \\
\text { tolerar tolices. }\end{array}$ & 10 & $\begin{array}{l}\text { Esperto ao fazer } \\
\text { coisas com matérias } \\
\text { comuns. }\end{array}$ & 08 & $\begin{array}{l}\text { Inquisitivo, cético, curioso } \\
\text { sobre como e por que das } \\
\text { coisas. }\end{array}$ \\
\hline 12 & $\begin{array}{l}\text { Entende a impor- } \\
\text { tância da natureza } \\
\text { (tempo, lua, sol, } \\
\text { estrelas, solo, etc.) }\end{array}$ & 11 & $\begin{array}{l}\text { Habilidades nas } \\
\text { artes (música, dança, } \\
\text { desenho, etc.) }\end{array}$ & 09 & $\begin{array}{l}\text { Adapta-se a uma variedade } \\
\text { de situaçóes e novos } \\
\text { ambientes. }\end{array}$ \\
\hline 13 & $\begin{array}{l}\text { Vocabulário excep- } \\
\text { cional, verbalmente } \\
\text { fluente. }\end{array}$ & 17 & Flexível, aberto. & 15 & $\begin{array}{l}\text { Trabalhador independen- } \\
\text { te, mostra iniciativa. }\end{array}$ \\
\hline 14 & $\begin{array}{l}\text { Aprende facilmente } \\
\text { novas línguas. }\end{array}$ & 19 & $\begin{array}{l}\text { Mostra insight e per- } \\
\text { cepçôes incomuns. }\end{array}$ & 18 & $\begin{array}{l}\text { Versátil, muitos interesses, } \\
\text { além da idade cronológica. }\end{array}$ \\
\hline 16 & $\begin{array}{l}\text { Bom julgamento, } \\
\text { lógico. }\end{array}$ & 22 & $\begin{array}{l}\text { Resiste à rotina e } \\
\text { repetição. }\end{array}$ & 20 & $\begin{array}{l}\text { Demonstra alto nível de } \\
\text { sensibilidade e empatia em } \\
\text { relaçáo aos outros. }\end{array}$ \\
\hline 21 & $\begin{array}{l}\text { Apresenta excelente } \\
\text { senso de humor. }\end{array}$ & -.-_ & -...-...-..- & 24 & $\begin{array}{l}\text { Sensível à verdade e à } \\
\text { honra. }\end{array}$ \\
\hline 23 & $\begin{array}{l}\text { Expressa ideias e } \\
\text { reaçôes, frequen- } \\
\text { temente de forma } \\
\text { argumentativa. }\end{array}$ & $\cdots$ & & ----- & \\
\hline
\end{tabular}

Quadro 2 - Indicadores* e traços de comportamento da Teoria dos Três Anéis**

Legenda:

*Indicadores de Altas Habilidades/Superdotação (MARQUES, 2011)

**Teoria dos Três Anéis (RENZULLI, 1978)

\section{Resultados E discussáo}

Considerando que foi tido por objetivo identificar as características conjugadas de AH/S e DV em crianças pela perspectiva de suas máes, a investigação foi pautada na percepção dos pais em relação às capacidades de seus filhos com DV. A partir da seleção dos indicadores de AH/S pelos pais, para cada um dos Anéis foram destacados os resultados apresentados por três máes que selecionaram o maior número de indicadores nas três áreas apresentadas na Teoria dos 
Três Anéis, Renzulli (1978), a saber: Habilidade Acima da Média; Criatividade e Envolvimento com a Tarefa.

Tabela 1 - Mães participantes e suas indicaçóes por área propostas na Teoria dos Três Anéis (RENZULLI, 1978)

\begin{tabular}{lcccc}
\hline Código & $\begin{array}{c}\text { Anel 1 } \\
\text { Habilidades acima da média }\end{array}$ & $\begin{array}{c}\text { Anel 2 } \\
\text { Criatividade }\end{array}$ & $\begin{array}{c}\text { Anel 3 } \\
\text { Envolvimento com a tarefa }\end{array}$ & $\begin{array}{c}\text { TOTAL } \\
\text { GERAL }\end{array}$ \\
\hline P07 & 08 & 05 & 07 & $\mathbf{2 0}$ \\
P08 & 07 & 03 & 07 & $\mathbf{1 7}$ \\
P11 & 07 & 05 & 06 & $\mathbf{1 8}$ \\
\hline
\end{tabular}

Fonte: elaboração própria.

Ao serem examinados os dados da Tabela 1, é verificada a proximidade de seleção de atribuição de indicadores realizados pelas três mães. Houve uma diferença máxima de quatro atribuiçóes de indicadores (20 a 17) e uma diferença mínima de indicação entre a mãe que atribuiu o menor número de indicadores (17) e aquela que atribuiu o número imediatamente superior (18) de AH/S.

As Tabelas 2, 3 e 4 apresentam, respectivamente e em sequência, as atribuições das mães de indicadores associados a cada um dos Três Anéis: Habilidade Acima da Média; Criatividade e Envolvimento com Tarefas. Todas apresentam o código de identificação dos participantes seguido dos números dos indicadores (IN) em ordem crescente (IN01; IN06; IN07; e assim por diante), com o total de indicaçóes na penúltima coluna e o total geral de indicadores nos Três Anéis, na última coluna.

A Tabela 2 apresenta a escolha dos indicadores pelas mães referentes ao Anel Habilidades Acima da Média. As mães P08 e P11 apontaram sete indicadores, e P07 apontou oito indicadores. As três mães selecionaram o IN01 (Aprende fácil e rapidamente), o IN06 (Persuasivo, capaz de influenciar os outros), IN12 (Entende a importância da natureza (tempo, lua, sol, estrelas, solo, etc.)), IN13 (Vocabulário excepcional, verbalmente fluente), IN16 (Bom julgamento, lógico) e o IN21(Apresenta excelente senso de humor). P08 e P11, que fizeram o mesmo número de indicaçóes neste anel, diferençaram-se pela seleção de IN07 (Mostra senso comum; pode não tolerar tolices), por P08, e o IN23 (Expressa ideias e reações, frequentemente de forma argumentativa), por P11.

Tabela 2 - Indicadores selecionados pelas mães para o Anel Habilidade acima da média

\begin{tabular}{lcccccccccc}
\hline CÓD & IN & IN & IN & IN & IN & IN & IN & IN & IN & T \\
& $\mathbf{0 1}$ & $\mathbf{0 6}$ & $\mathbf{0 7}$ & $\mathbf{1 2}$ & $\mathbf{1 3}$ & $\mathbf{1 4}$ & $\mathbf{1 6}$ & $\mathbf{2 1}$ & $\mathbf{2 3}$ & \\
\hline P07 & 1 & 1 & 1 & 1 & 1 & 0 & 1 & 1 & 1 & $\mathbf{8}$ \\
P08 & 1 & 1 & 1 & 1 & 1 & 0 & 1 & 1 & 0 & 7 \\
P11 & 1 & 1 & 0 & 1 & 1 & 0 & 1 & 1 & 1 & 7 \\
\hline
\end{tabular}

Fonte: elaboração própria. 
A Tabela 3 apresenta a escolha dos indicadores pelas mães referentes ao Anel Criatividade. Duas mães (P07 e P11) apontaram cinco indicadores, e P08 apontou três indicadores. As três mães selecionaram o IN02 (original, imaginativo, criativo, não convencional) e o IN11 (esperto ao fazer coisas com matérias comuns). P07 e P11, que fizeram o mesmo número de indicaçóes neste Anel, diferençaram-se pela seleção de IN04 (pensa de forma incomum para resolver problemas), por P07, e de IN10 (esperto ao fazer coisas com matérias comuns), por P11.

Tabela 3 - Indicadores selecionados pelas mães para o Anel Criatividade

\begin{tabular}{lllllllll}
\hline CÓD & IN & IN & IN & IN & IN & IN & IN & T \\
\hline P07 & 1 & 1 & 04 & 1 & 1 & 0 & 1 & $\mathbf{0 5}$ \\
P08 & 1 & 0 & 0 & 1 & 0 & 1 & 0 & $\mathbf{0 3}$ \\
P11 & 1 & 0 & 1 & 1 & 1 & 0 & 1 & $\mathbf{0 5}$ \\
\hline
\end{tabular}

Fonte: elaboração própria.

A Tabela 4 apresenta a escolha dos indicadores pelas mães referentes ao Anel Envolvimento com tarefas. Duas mães (P07 e P08) apontaram sete indicadores, e P11 apontou seis indicadores. As três mães selecionaram o IN05 (Persistente, independente, autodirecionado - faz coisas sem que seja mandado), o IN08 (Inquisitivo, cético, curioso sobre como e por que das coisas), o IN09 (Adapta-se a uma variedade de situaçóes e novos ambientes), o IN20 (Demonstra alto nível de sensibilidade e empatia em relação aos outros) e o IN24 (Sensível à verdade e à honra). P07 e P08, que fizeram o mesmo número de indicaçóes neste Anel, não tiveram nenhuma diferença na escolha dos indicadores.

Tabela 4 - Indicadores selecionados pelas mães para o Anel Envolvimento com Tarefas

\begin{tabular}{lccccccccc}
\hline CÓD & IN & IN & IN & IN & IN & IN & IN & IN & T \\
\hline P07 & 1 & 1 & 1 & 1 & 0 & 1 & 1 & 1 & $\mathbf{0 7}$ \\
P08 & 1 & 1 & 1 & 1 & 0 & 1 & 1 & 1 & $\mathbf{0 7}$ \\
P11 & 0 & 1 & 1 & 1 & 1 & 0 & 1 & 1 & $\mathbf{0 6}$ \\
\hline
\end{tabular}

Fonte: elaboração própria.

As três mães indicaram que seus filhos apresentaram bom desempenho em relação ao conjunto de traços de comportamento referidos na Teoria dos Três Anéis (RENZULLI, 1978). Quanto ao anel de Habilidade Acima da Média, as escolhas foram elevadas, sugerindo que, se solicitadas, as mães identificam as habilidades existentes e potenciais de seus filhos com DV. Quando Renzulli (2005) usa a expressão Habilidade Acima da Média, refere-se tanto às capacidades que os indivíduos já possuem quanto ao potencial para desenvolver habilidades em alguma área específica. $\mathrm{O}$ reconhecimento das habilidades pelos pais remete à discussão sobre o desenvolvimento do potencial da criança com DV. Guenther (2006) esclarece que para um 
talento humano se desenvolver e tornar-se produção superior precisa primeiramente ser identificado, estimulado e acompanhado, caso contrário será desperdiçado. Não basta identificar o potencial dos filhos com DV. Necessita-se da ação dos pais para a promoção de experiências enriquecedoras e estimuladoras.

O conhecimento limitado de muitos pais em relação ao potencial de seus filhos com DV os torna céticos em relação à possibilidade da conjunção de duas características de excepcionalidade, ou seja, DV e AH/S, de acordo com Johnson e Corn (1989).

A análise das indicações dos pais mostra que foi selecionado menor número de indicadores para o Anel Criatividade (Tabela 3). A Criatividade compóe a maior parte das realizaçóes significativas, também presente como traço de comportamento na concepção dos Três Anéis (RENZULLI, 1978). Requer originalidade de pensamento, aptidão para deixar de lado as convençóes e talento para projetar e realizar projetos originais.

Segundo Cunha e Enumo (2003), a exploração é um recurso de fundamental para o desenvolvimento das habilidades criativas da criança com DV, e seu padrão de desenvolvimento está associado à influência do ambiente desde o seu nascimento. Rettig (1994) apresentou estudos de crianças com DV que mostram atraso em atividades que exigem imaginaçáo e criatividade, mas para Nunes e Lomônaco (2008) muitas dessas defasagens se devem à falta de informação dos pais de que o potencial de seu filho com DV pode ser desenvolvido quando bem explorado, evitando assim ser desperdiçado.

Em relação ao terceiro Anel, Comprometimento com a Tarefa, Renzulli (1998) afirma que envolve: perseverança, resistência, trabalho árduo, dedicação, autoconfiança, e uma convicção na própria habilidade para concluir um trabalho importante. Esses comportamentos foram indicados pelas mães como presentes no cotidiano de seus filhos em um número muito próximo àquele das indicaçóes para Habilidades Acima da Média (Tabela 1).

As indicações das mães foram feitas sob condições de solicitação de que se manifestassem de acordo com os instrumentos utilizados nesta pesquisa. É possível afirmar que se trata de uma seleção "induzida" pela demanda da pesquisa, e este fato não diminui a força de se verificar que os pais identificam indicadores de AH/S no desempenho dos seus filhos com DV. Entretanto, uma medida adicional poderia contribuir para caracterizar a dupla excepcionalidade AH/S e DV em crianças pela perspectiva de seus pais.

Reconhecendo os limites da adaptação de instrumentos de medida que não estão validados para a população brasileira, considerou-se que o desempenho das crianças com DV na subescala Verbal do WISK III, adaptada por Nascimento e Flores-Mendonza (2007) poderia ser uma informação adicional para a associação de AH/S e DV. Os resultados obtidos pelas crianças foram organizados na Tabela 5, que apresenta o número de indicadores selecionados para cada um dos Anéis e o total obtido nos subtestes da Escala Verbal do WISK III. 
Tabela 5 - Número de indicadores AH/S e resultado da Escala Verbal do WISK III adaptado

\begin{tabular}{lccccc}
\hline Participantes & $\begin{array}{c}\text { Habilidade } \\
\text { acima da média } \\
\text { (9 Itens) }\end{array}$ & $\begin{array}{c}\text { Criatividade } \\
\text { (7 Itens) }\end{array}$ & $\begin{array}{c}\text { Envolvimento } \\
\text { com a tarefa } \\
\text { (8 Itens) }\end{array}$ & $\begin{array}{c}\text { Tg } \\
\mathbf{2 4}\end{array}$ & $\begin{array}{c}\text { Qi } \\
\text { Escala verbal } \\
\text { - adaptada } \\
\text { Wisk }\end{array}$ \\
\hline P07 & 08 & 05 & 07 & $\mathbf{2 0}$ & $\begin{array}{c}\mathbf{8 6} \text { (média } \\
\text { inferior)* }\end{array}$ \\
P08 & 07 & 03 & 07 & $\mathbf{1 7}$ & $\begin{array}{c}\mathbf{7 6} \text { (limítro- } \\
\text { fe)* } \\
\text { P11 }\end{array}$ \\
\hline
\end{tabular}

Fonte: elaboração própria.

Legenda:

*Distribuição de QI Verbal em Nascimento e Flores-Mendonza (2007, p. 630).

Para fins de pesquisa, a superdotação intelectual foi definida nos Testes de QI (WISK III) com uma pontuação acima de 130. Todos os participantes pontuaram em níveis insuficientes para serem classificados no limite superior (130) da categoria superior (120-130), que lhes conferiria a posição de AH/S. Os resultados nos subtestes do WISK III mostram ainda que cada participante pontuou em categorias diferentes, embora dois deles na categoria média (superior - P11; inferior - P07), embora fossem percebidos pelos seus pais com indicadores de AH/S.

Algumas consideraçóes são relevantes para melhor compreensão dos resultados de acordo com alguns elementos destacados na literatura e adequados a esta conjuntura: (a) o olhar dos pais em relação ao desenvolvimento de seu filho com DV; (b) os instrumentos utilizados para a avaliação de crianças com DV.

Goodnow (1996) tratou da importância das crenças parentais para a compreensão dos aspectos relacionados à cognição do DV. Meduros e Salomão (2012, p. 12) esclarecem que as mães de crianças com DV apresentam, quando bem orientadas, "[...] verbalizaçóes positivas em relação ao desenvolvimento atual do filho DV" e visão otimista para o futuro, uma vez que elas os avaliam comparando as dificuldades que tiveram no passado com o momento atual".

As mães que participaram do estudo faziam parte das atividades da ONG frequentada pelos filhos, tendo participação ativa na vida escolar dos filhos. Todas elas falaram do sucesso que seus filhos apresentaram tanto na ONG quanto na escola regular que frequentavam. Esta informação, associada ao número de indicadores, poderia gerar uma expectativa de resultados próximos à faixa de superdotação no teste de QI, entretanto, conforme destacam Cunha e Enumo (2003), o desenvolvimento da criança com DV inicia-se com a exploração de suas habilidades e as influências do ambiente desde o seu nascimento. Ela necessita de muitos estímulos para a construção de suas representações em função da ausência da visão, que vai acontecendo gradativamente de acordo com o avanço da idade.

Pelo fato de vivermos em um mundo organizado para e por pessoas com sistema visual íntegro, a criança com DV, principalmente nos primeiros anos de vida, pode ainda não demonstrar todo potencial como uma criança vidente. 
Outro ponto a ser considerado refere-se à impropriedade de empregar testes de QI para pessoas com DV. Segundo Johnson (1987) e Maker (1977), a própria identificação do potencial da pessoa com DV pode ser um obstáculo em função da limitação dos testes, uma vez que as medidas utilizadas para auxiliar na identificação reconhecem prioritariamente a capacidade, e não o potencial do indivíduo. Esta ideia é confirmada por Vialle e Paterson (1996), que questionam a falta de programas adequados para pessoas com DV, pois idade e conceitos podem alterar os resultados dos testes. Os resultados obtidos indicam, sobretudo, a importância de se investir em procedimentos ou instrumentos de avaliação das capacidades instaladas e potenciais das crianças com DV.

\section{Consideraçótes finais}

As mães das crianças com DV selecionaram indicadores de AH/S para os Três Anéis propostos por Renzulli (1998), embora seus filhos fossem classificados nos subtestes do WISK III nas categorias média (superior e inferior) e limítrofe. A relevância destes resultados está a possibilidade de conjugar as características da pessoa com DV com aquelas das pessoas identificadas com AH/S na perspectiva daqueles que com elas convivem.

Confirmando a literatura, os dados sugerem que a baixa expectativa dos pais de crianças com DV pode ser superada. A literatura tem apontado que crianças com DV têm sido rotuladas pelas suas desvantagens, e não pelas suas possibilidades. $\mathrm{O}$ desconhecimento sobre as possibilidades dessas crianças gera uma concepção inadequada, atribuindo a todas as mesmas características e incapacidades, fator que gera nos pais baixa expectativa em relação ao desempenho de seus filhos com DV, limitando, assim, a qualidade das interaçóes que são estabelecidas entre eles (CUNHA; ENUMO; CANAL, 2007). Esse contexto gera o risco de atender esses aprendizes somente em suas dificuldades e, como consequência, obscurecer seus talentos.

Diferentemente dessa conjuntura, neste estudo as mães demonstraram altas expectativas em relação às potencialidades de seus filhos. Por meio das escolhas dos indicativos de AH/S, elas perceberam possibilidades dos filhos referentes aos Anéis Habilidades Acima da Média, Criatividade e Envolvimento com as Tarefas. Essas mães percebem seus filhos com DV como crianças plenamente capazes, apesar da deficiência visual.

Não cabe no escopo deste estudo buscar as razões pelas quais as mães têm uma percepção tão positiva em relação às potencialidades de seus filhos com DV, vislumbrando a possibilidade de dupla excepcionalidade. Porém, dois aspectos destacam-se: a formação escolar das mães e a participação em uma instituição especializada.

A literatura aponta que as crenças e concepções dos pais estão associadas ao seu nível de escolarização (RIBAS JÚNIOR; SEIDL DE MOURA; BORNSTEIN, 2007). Quanto maior a escolaridade, melhores são as percepçóes de possibilidades e maiores as expectativas quanto ao desenvolvimento dos seus filhos com DV. Neste estudo, as mães participantes tinham um nível médio de formação, entretanto, participavam de orientações em uma instituição especializada. A ONG oferecia tanto o atendimento especializado para os filhos como orientação para todos os pais o que poderia contribuir para o desenvolvimento positivo de suas concepçóes e suas expectativas em relação às potencialidades de seus filhos, permitindo considerar a possibilidade de dupla excepcionalidade (WHITMORE; MAKER, 1985; JOHNSON; CORN, 1989). 
Ao serem comparados os resultados da seleção pelas mães dos indicadores de $\mathrm{AH} / \mathrm{S}$ com os resultados dos subtestes da Escala Verbal do WISK III, estes não apresentaram escores suficientes para que os filhos fossem considerados superdotados como sugeririam os indicadores selecionados. Apesar dos ganhos de se ter uma parte do WISK III adaptada para crianças com DV, em um trabalho rigoroso realizado por Nascimento e Flores-Mendoza (2007), a dificuldade de avaliação do funcionamento intelectual padronizado de crianças com DV deverá ser considerada uma das fragilidades do estudo por contar apenas com parte da avaliaçáo possível com a aplicação do WISC III (JOHNSON; CORN, 1989).

Ressalta-se que a identificação da competência de seus filhos com DV pelas mães fortalece a necessidade de se enfrentar o desafio de investigar a dupla excepcionalidade na associação da deficiência visual com altas habilidades/superdotação. Da discrepância dos resultados, destaca-se que a percepção positiva das mães pode orientar a atenção para as potencialidades das crianças com DV e para a valorização das suas competências e habilidades.

\section{REFERÊNCIAS}

ALMEIDA, M.A.; CAPELLINI, V.L.M.F. Alunos talentosos: possíveis superdotados não notados. Revista Educação, Porto Alegre, v.28, n.1(55), p.45-64, 2005.

ASPESI, C.C. A família do aluno com altas habilidades. In: FLEITH, D. S. (Org.). A construção de práticas educacionais para alunos com altas habilidades/superdotação: o aluno e a família. Brasília, DF, Ministério da Educação, Secretaria de Educação Especial, 2007. v.3.

BATISTA, C.G.; ENUMO, S.R.F. Desenvolvimento humano e impedimentos de origem orgânica: o caso da deficiência visual. In: NOVO, H.A.; MENANDRO, M.C.S. (Org.). Olhares diversos: estudando o desenvolvimento humano. Vitória: UFES, 2000. p.157-174.

COELHO, T.P.C.; BARROCO, S.M.S.; SIERRA, M.A. O conceito em compensação em L. S. Vygotsky e suas implicaçóes para educação de pessoas cegas. In: CONPE, 10., 2011. Anais... 2011.

CUNHA, A.C.B.; ENUMO, S.R.F. Desenvolvimento da criança com deficiência visual e interação mãe-criança: algumas consideraçóes. Psicologia, Saúde e Doenças, Lisboa, v.4, n.1, p.33-46, 2003.

CUNHA, A.; ENUMO, S.R.; CANAL, C. Concepçóes de mães sobre desenvolvimento infantil e desempenho cognitivo de filhos com deficiência visual, em situação de avaliação assistida e tradicional. Revista FAEEBA: Educação e Contemporaneidade, Salvador, v.16, n.27, p.223-238, 2007.

DESSEN, M. A. Desenvolvimento familiar: transição de um sistema triádico para poliádico. Temas em Psicologia, n.3, p.51-61, 1997.

GERMANI, L. M. B. Características de altas habilidades/superdotação e de déficit de atençãol hiperatividade: uma contribuição à família e a escola. 2006. 178f. Dissertação (Mestrado em Educação) - Faculdade de Educação, Programa de Pós-Graduação em Educação, Pontifícia Universidade Católica do Rio Grande do Sul, Porto Alegre, 2006.

GOODNOW, J. From household practices to parents' ideas about work and interpersonal relationships. In: HARKNESS, S.; SUPER, C. (Org.). Parents' cultural belief systems: their origins, expressions, and consequences. New York: The Guilford Press, 1996.

GUENTHER, Z.C. Educação de bem dotados: alguns conceitos básicos. Psicopedagogia, v.1, n.2, p.30-38, 2003. 
GUENTHER, Z.C. Capacidade e talento: um programa para a escola. São Paulo: EPU, 2006.

HALLAHAN, D.P.; KAUFFMAN, J.M. Exceptional learners: introduction to special education. Boston: Allyn e Bacon, 2003.

JOHNSON, L. Teaching the visually impaired gifted youngster. Journal of visual impairment and blindness, v.81, n.2, p.51-52, 1987.

JOHNSON, L.; CORN, A.L. The past, present, and future of education for gifted children with sensory and/or physical disabilities. Roeper Review: A Journal on Gifted Education, v.12, n.1, p.13-23, 1989.

KREPPNER, K. Development in a developing context: Rethinking the family's role for the children's development. In: WINEGAR, L.T.; VALSINER, J. (Org.). Children's development with in social, 1992.

KREPPNER, K. The child and the family: interdependence in developmental pathways. Psicologia: Teoria e Pesquisa, n.16, p.11-22, 2000.

KREPPNER, K. Social relations and affective development in the first two years in family contexts. In: VALSINER, J.; CONNOLLY, K.J. (Org.). Handbook of developmental psychology, Londres: Sage, 2003. p.194-214.

LEWIS, V. Development and disability. 2. ed. Oxford: Blackwell, 2003.

MAKER, C. J. Providing programmes for the gifted handicapped. Virginia: council for exceptional children, 1977.

MARQUES, C. R. Levantamento de indicadores de crianças com altas habilidades e superdotação em Juquiticabal/São Paulo. 2011.167f. Dissertação (Mestrado em Educação Especial) - Universidade Federal de São Carlos, São Carlos, 2011.

MEDUROS, C.S.; SALOMÃO, N.M.R. Concepçóes maternas sobre o desenvolvimento da criança com deficiência visual. Revista Brasileira de Educação Especial, Marília, v.18, n.2, p. 283-300, 2012.

NAVARRO, R.P.; MILLÁN, R. Inferential functioning in visually impaired children. Research in Developmental Disabilities, Baton Rouge, v.28, n.1, p.249-265, 2007.

NASCIMENTO, E. Adaptação, validação e normatização do WAIS-III para uma amostra brasileira. In: WECHSLER, D. (Org.). WAIS-III: manual para administração e avaliação. São Paulo: Casa do Psicólogo, 2004.

NUNES, S.S.; LOMÔNACO, J.F.B. Desenvolvimento de conceitos em cegos congênitos: caminhos de aquisição do conhecimento. Psicologia Escolar e Educacional, Maringá, v.12, n.1, p.119-138, 2008.

OUROFINO, V. T. A. T. Altas habilidades e hiperatividade: a dupla excepcionalidade. In: FLEITH, D.S.; ALENCAR, E.M.L.S. (Org.). Desenvolvimento de talentos e altas habilidades: orientação a pais e professores. Porto Alegre: Artmed, 2007. p.46-54.

PÉREZ-PEREIRA, M.; CONTI-RAMSDEN, G. Language Development and Social Interaction in Blind Children. Psychology Press, East Sussex, 2008.

RENZULLI, J.S. What makes giftedness? Re-examining a definition. Phi Delta Kappan, n.60, p.180184, 1978.

RENZULLI, J.S. The three ring conception of giftedness: A developmental model for creative productivity. In: STERNBERG, R.J.; DAVIDSON, J.E. (Eds.). Conceptions of giftedness. New York: Cambridge University Press, 1986. p.53-92. 
RENZULLI, J.S. Superdotação, e como a desenvolvemos? Uma retrospectiva de vinte e cinco anos. Educação, Porto Alegre, v.27, n.1 (52), p.75-131, 2004.

RETTIG, M. The play of young children with visual impairments: characteristics and interventions. Journal of Visual Impairment \& Blindness, Baltimore, v.88, n.9, p.410-420, 1994.

RIBAS JÚNIOR, R.C.; SEIDL DE MOURA, M.L.; BORNSTEIN, M.H. Cogniçóes maternas acerca da maternidade e do desenvolvimento humano: uma contribuiçáo ao estudo da psicologia parental. Revista brasileira de crescimento e desenvolvimento humano, São Paulo, v.1, n.1, 2007.

RODRIGO, M.J.; PALACIOS, J. Familia y desarrollo humano. Madrid: Alianza Editorial, 2003.

SHANG-PING, L.; ANJOO, S. The gifted-visually Handicapped Child: a review of literature. In: ANNUAL MEETING OF THE MID-SOUTH EDUCATION RESEARCH ASSOCIATION, 1992, Knoxville. Proceedings... 1992.

SMITH, D. D. Introdução à educação especial: ensinar em tempos de exclusão. 5.ed. Porto Alegre: Artmed, 2008.

SILVERMAN, L.K. Gifted children with learning disabilities. In: COLANGELO, N.; DAVIS, G.A. (Eds.). Handbook of gifted education. 3rd ed. Boston: Allyn e Bacon, 2003. p.533-543.

VIALLE, W.; PATERSON, J. A Sign of the future: Recognizing the intellectual strengths of the Deaf. Journal of Educational the Deaf, Australian, v.2, n.2, p.32-37, 1996.

VIRGOLIM, A. M. R. Altas habilidades/superdotação: encorajando potenciais. Ministério de Educação - MEC, Secretaria de Educação Especial - SEESP, Brasília, DF, 2007.

VYGOTSKY, L. S. Fundamentos de defectología. Obras Completas, tomo cinco (2. reimp.). Cuba: Editorial Pueblo y Educación, 1997.

WARREN, D. H. Blindness and children: An individual difference approach. Cambridge: Cambridge University Press, 1994.

WHITMORE, J.R.; MAKER, C.J. Intellectual giftedness in disabled persons. Rockville: Aspen Systems Corp, 1985.

WINNER, E. Crianças superdotadas. Mitos e realidades. Porto Alegre: Artmed, 1998.

Recebido em: 16/03/2015

Reformulado em: 18/04/2016

Aprovado em: 29/04/2016 
LOPES, B.J.S. \& GIL, M.S.C.A. 